\title{
A New Application of Photogrammetry in the Underground Pipe Network Survey
}

\author{
Yongrong Li ${ }^{\mathrm{a}}{ }^{\mathrm{c}}$, , Qiang Feng ${ }^{\mathrm{b}}$, Ning Zhang ${ }^{\mathrm{d}}$,Hui Tian ${ }^{\mathrm{c}}$,Ying Yang ${ }^{\mathrm{c}}$, Junjie Jin ${ }^{\mathrm{e}}$,Ying $\mathrm{LI}^{\mathrm{f}}$,Liyun Zhang ${ }^{\mathrm{c}}$ \\ ${ }^{\text {a }}$ Chinese Academy of Surveying \& Mapping, No 16 Beitaiping Road, Beijing,China \\ ${ }^{b}$ Beijing tongchuangda surveying Co. Ltd, North Third Ring Road, Beijing, China \\ ${ }^{c}$ Beijing surveying and mapping spatial information technology Co. Ltd. \\ d China Land Surveying and Planning Institute, Zhangning@clspi.rog.cn \\ ${ }^{\mathrm{e}}$ Fragrant Hill Park, No. 40 Maimai Street,Beijing,China \\ ${ }^{\mathrm{f}}$ Liaoning Technical University Fuxin City, Liaoning Province, China Road, No. 47, China
}

Commission V, WG V/5

KEY WORDS: Photogrammetric Instrument, Underground Pipe Survey, Secure and Efficient

\begin{abstract}
:
This paper mainly introduces a device that can be used for underground pipeline survey task. through the cameras installed on the device, we can obtain stereo synchronous shooting images, and then use the method of close range photogrammetry to investigate and measure underground objects. During working process, the staff put the camera into the well and to control camera shooting from the ground. Greatly improve work efficiency, at the same time to avoid the underground toxis gas damage to people. The main content of this paper includes three parts: hardware design, software development and test production.
\end{abstract}

\section{INTRODUCTION}

Aerial basic photogrammetry theory has been developed relatively perfect. In the application, the photogrammetry task is to solve the obtaining images and mapping on the ground, that later close range photogrammetry is similar in aerial photogrammetry. At present, few articles and application examples to investigate underground pipeline network in photogrammetry mothed.

\section{WELL CAMERA RESEARCH AND DEVELOPMENT}

\subsection{WELL CAMERA DESIGN}

There are 20 micro focal length cameras $(4 \mathrm{~mm})$ placed in downhold position, 8 pairs are placed around ,and 1 pair is installed upward, another is downward. Thus the downhold camera can get panoramic photos for the pipe in the bottom of well. Taking into account the lighting and position underground well, 10 LED lights and 12 laser pens are placed in appropriate position on the downhold camera. Through the WiFi the operator can momitor the movement of the camera in the well, use workstation on the ground select a appropriate position to control 20 cameras take photos at the same time. and then transfer images back to the workstation wireless.

\subsection{WORKING CAR}

When working outdoors, it is needed to design a working platform for setting and controlling the movements of the camera. Taking into account the size of the majority of the wellhead, the size of the car $1.5 * 0.8 * 1.0$ meters (long * wide * high) can meet the needs of the outside working. The Mechanical and electronic controller which provide convenience for the operator are placed on the working car.In the process of downward movement of the underground camera, operator can find appropriate location from the monitor screen to control it takes picture. If it is too dark, operator can open the LED light to illuminate, e,g. Figure 1.

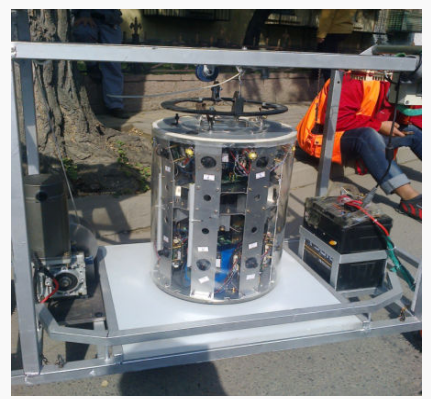

Figure 1

\subsection{THE ESTABLISHMENT OF CALIBRATION FIELD}

In photogrammetry, it is necessary to correct distortion of camera's optical lens, especially to micro focal length cameras. According to the camera characteristics, set up a full range of indoor 3D control field, e.g. Figure 2. 


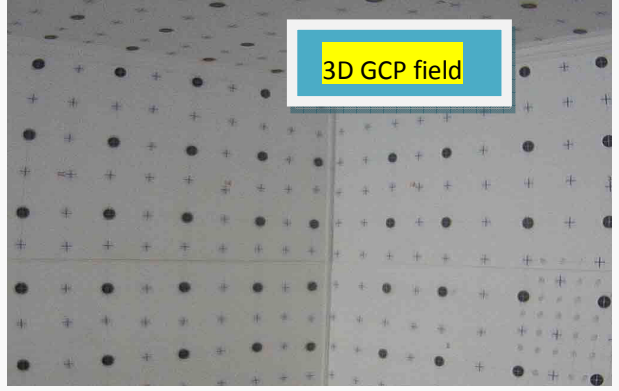

Figure 2

\section{Sotfware development}

camera parameters solution are including Lens optical Distortion difference $(\mathrm{k} 1, \mathrm{k} 2, \mathrm{p} 1, \mathrm{p} 2, \mathrm{a}, \mathrm{b})$, single image interior orientation elements $(\mathrm{x} 0, \mathrm{Y} 0, \mathrm{f})$ and elements of exterior orientation (Xs, Ys, Zs,phi,omga, kap). Self calibration bundle adjustment method is used during the development process (LIN Z J, 2008) . using known GCP coordinates (X,Y,Z), Camera position and corresponding image's coordinate, we can use collinear equation:

$$
\left\{\begin{array}{l}
\left(x+v_{x}\right)+\Delta \mathrm{x}=-f \frac{a_{1}(X-X s)+b_{1}(Y-Y s)+c_{1}(Z-Z s)}{a_{3}(X-X s)+b_{3}(Y-Y s)+c_{3}(Z-Z s)} \\
\left(y+v_{y}\right)+\Delta y=-f \frac{a_{2}(X-X s)+b_{2}(Y-Y s)+c_{2}(Z-Z s)}{a_{3}(X-X s)+b_{3}(Y-Y s)+c_{3}(Z-Z s)}
\end{array}\right.
$$

$\Delta \mathrm{x}, \quad \Delta \mathrm{y}$-- image correction;

$\mathrm{x}, \mathrm{y}$--image coordinate;

f --camera focal length;

$$
\begin{gathered}
\begin{array}{c}
\Delta y=\left(y-y_{0}\right)\left(k_{1} r^{2}+k_{2} r^{4}\right)+p_{2}\left[r^{2}+2\left(y-y_{0}\right)^{2}\right]+ \\
2 p_{1}\left(x-x_{0}\right)\left(y-y_{0}\right)+a\left(y-y_{0}\right) \\
\Delta x=\left(x-x_{0}\right)\left(k_{1} r^{2}+k_{2} r^{4}\right)+p_{1}\left[r^{2}+2\left(x-x_{0}\right)^{2}\right]+ \\
2 p_{2}\left(x-x_{0}\right)\left(y-y_{0}\right)+\alpha\left(x-x_{0}\right)+\beta\left(y-y_{0}\right)
\end{array}
\end{gathered}
$$

$\mathrm{x}_{0}, \mathrm{y}_{0}--$ image origin coordinates;

$$
r=\sqrt{\left(x-x_{0}\right)^{2}+\left(y-y_{0}\right)^{2}}
$$

$k_{1}, k_{2}, \mathrm{p}_{1}, \mathrm{p}_{2}$-- distortion difference parameters;

The equation is calculated by iteration. At last we can obtain camera parameters-(k1,k2,p1,p2,a,b), (x0, Y0, f) and (Xs, Ys, Zs,phi,omga, kap) (Tianen Chen, 2007) .Different from the traditional aerial photogrammetry, downhole camera installed 20 cameras whick have different positions and orientations. So control points $(\mathrm{X}, \mathrm{Y}, \mathrm{Z})$ must be rotation and translation according to the needs of the different cameras position and angle, thus ensure accuracy of calculate exterior orientation elements, otherwise there will be no convergence, even wrong exterior elements value appeared (Feng W H,2001).

$$
\left(\begin{array}{c}
X_{\mathrm{t}} \\
Y_{\mathrm{t}} \\
Z_{\mathrm{t}}
\end{array}\right)=T_{\mathrm{x}} * T_{\mathrm{y}} * T_{\mathrm{z}} *\left(\begin{array}{c}
X \\
Y \\
Z
\end{array}\right)
$$

$T_{\mathrm{x}} * T_{\mathrm{y}} * T_{\mathrm{z}}--18$ cameras(exclude top 2 cameras) rotation matrix, around the $\mathrm{X}, \mathrm{Y}$ and $\mathrm{Z}$ axis.$X_{\mathrm{t}} Y_{\mathrm{t}} Z_{\mathrm{t}}^{-- \text {-control point coordinates }}$ after rotated. $\mathrm{X}, \mathrm{Y}, \mathrm{Z}$-- control point coordinates before rotated.

\section{2 the coordinates calculation of object points}

After the previous calculations, each image exterior orientation elements are known, then using stereo images EO and image coordinates to intersect unknown point ( $\mathrm{P}$ point) coordinates $\mathrm{P}(\mathrm{X}, \mathrm{Y}, \mathrm{Z})$, e.g.Figure 3 . due to the camera coordinate axises have been rotated befor calculation, that is to say, each stereo model has independent coordinate system. In order to keep measured value have same coordinate, we should to rotate calculated value $\mathrm{P}\left(\mathrm{X}_{\mathrm{p}}, Y_{\mathrm{p}}, Z_{\mathrm{P}}\right)$ back to the unified coordinate system $\mathrm{P}\left(\mathrm{X}_{\mathrm{U}}, Y_{\mathrm{V}}, Z_{\mathrm{W}}\right)$, according to the designed position and angle.

$\left(\begin{array}{c}X_{\mathrm{U}} \\ Y_{\mathrm{V}} \\ Z_{\mathrm{W}}\end{array}\right)=T_{\mathrm{z}} * T_{\mathrm{y}} * T_{\mathrm{x}} *\left(\begin{array}{c}X_{p} \\ Y_{p} \\ Z_{p}\end{array}\right)$

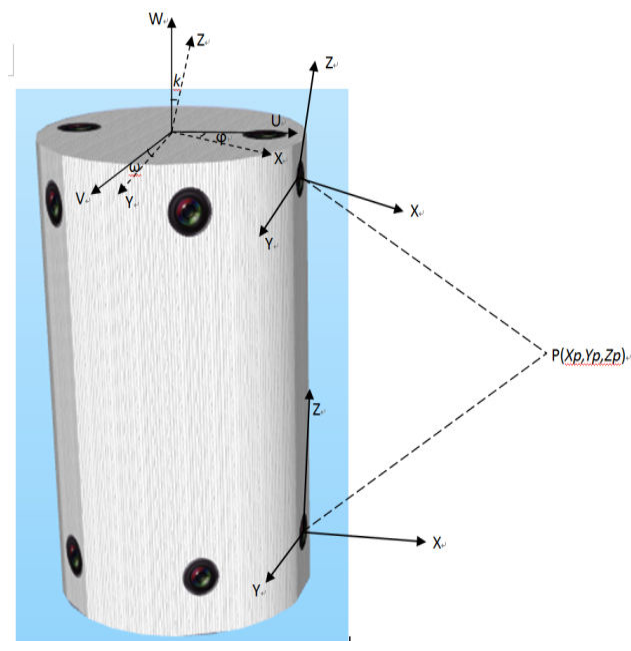

Figure 3

Thus, object points from different stereo model have unified coordinate system, the coordinate difference between two points cross stereo model is no problem 


\section{3 data management and human computer interaction.}

The convenience of human-computer interaction is one of most reference index whether a system can be successfully accepted by the user. It is very difficult to look for 20 images shot in one time. so, the software has a three-dimensional window to help operator quickly locate the target. In this window the measured objects also be showed Avoiding repeated measures. In addition, there is also a editing window, the operator can transform raw data collected from stereo model into the general format, so greatly improve efficiency, e.g. Figure 4

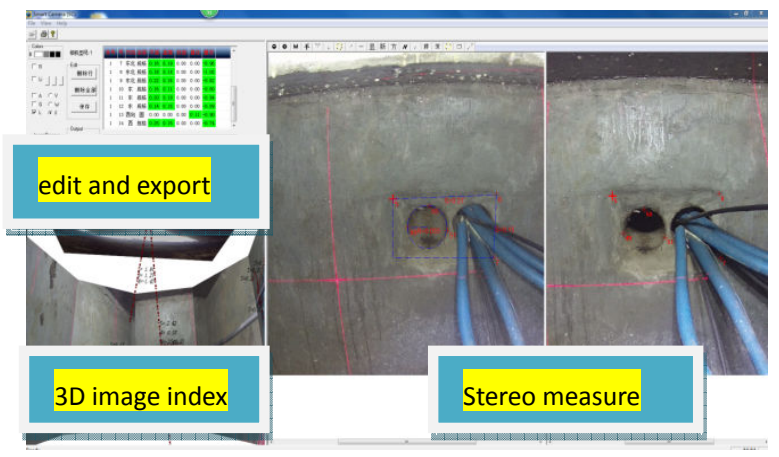

Figure 4

\section{1 experimente area choice}

\section{Testing and experimental production}

The experimentation area lies in beifengwo $\operatorname{Road}(1.2 \mathrm{~km}$ long),BeiJing, the area contains thermal wells, communication wells, sewage wells, water wells and so on,very representative.

\section{2 scheme and test}

The purpose of this experiment is to test the system's efficiency and to verify data 's accuracy, including hardware convenient operation, the camera environment adaptability, image clarity, software operability and final results uniformity. The wells were investigated simultaneously one by one .

The survey contents include: the pipeline length and width, radius, direction and depth (from well head to target). The following figure is a comparison of the traditional method and new method,e.g.Figure 5.

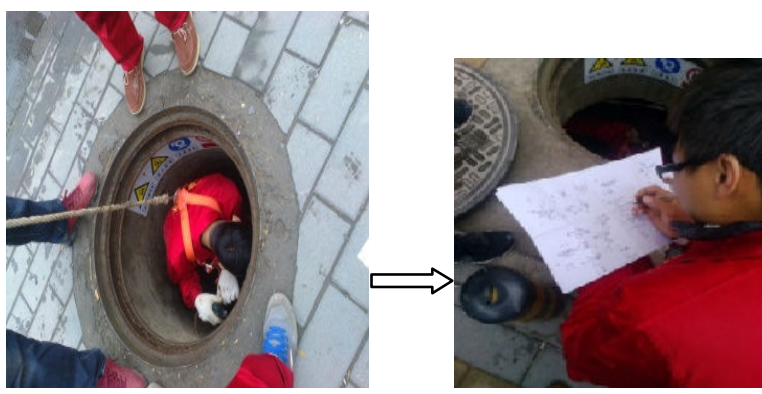

traditional method
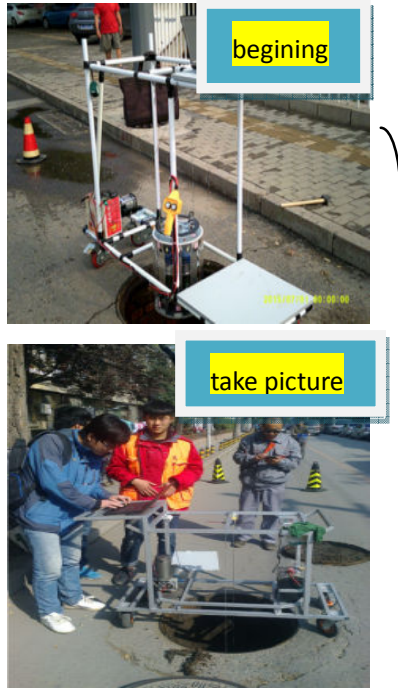

well camera method

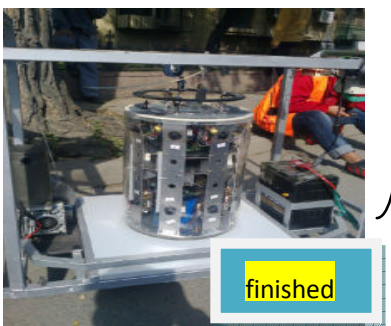

Figure 5

\subsection{Experimental result}

The Experimental results as shown below(parts of result),e.g. Figure 6.

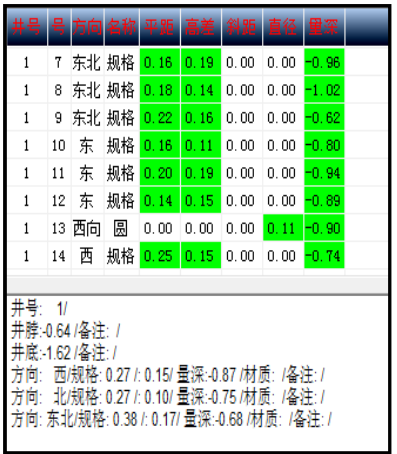

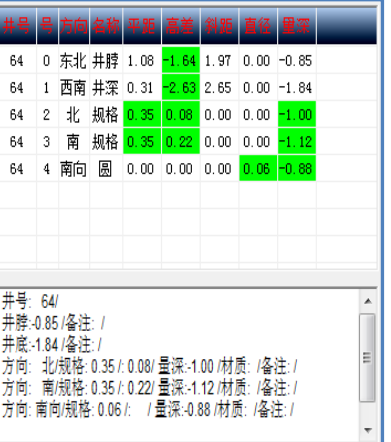

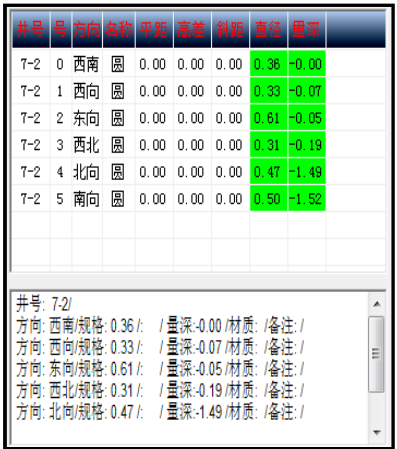

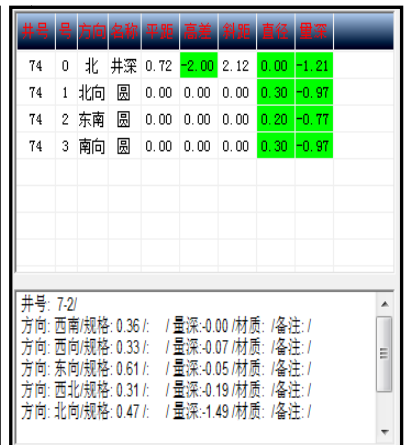



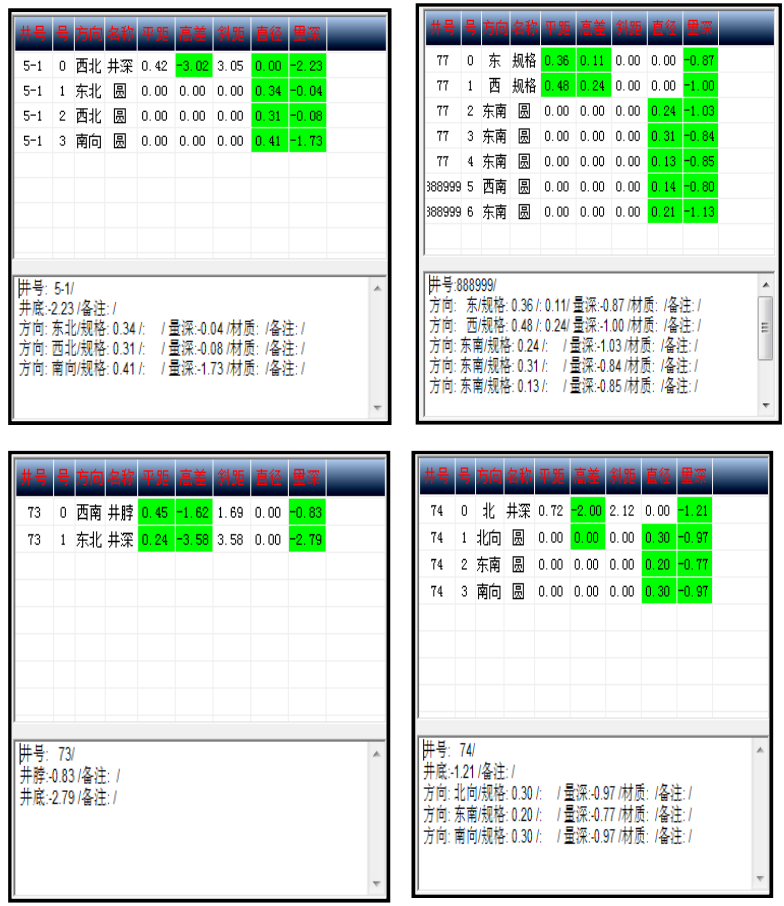

Figure 6

...... A total of 151 results.

Field work efficiency: according to 151 wells including Telecom, sewage, drainage, water supply and heating test, the efficiency begging from opening well lid - take photos -untill to be closed, e.g Table 1.

\begin{tabular}{|l|l|l|l|}
\hline $\mathrm{N}$ & $\begin{array}{l}\text { comparison } \\
\text { content }\end{array}$ & tradition & well camera \\
\hline 1 & tool & tape & well camera \\
\hline 2 & $\begin{array}{l}\text { Outdoor Spend } \\
\text { time/well }\end{array}$ & $\begin{array}{l}\text { average } 8 \\
\text { minute }\end{array}$ & $\begin{array}{l}\text { average 1.5 } \\
\text { minute }\end{array}$ \\
\hline 3 & $\begin{array}{l}\text { Within spend } \\
\text { time/well }\end{array}$ & $\begin{array}{l}\text { average 3.7 } \\
\text { minute }\end{array}$ & $\begin{array}{l}\text { average } \\
\text { 3minute }\end{array}$ \\
\hline 4 & accuracy & $1.2 \mathrm{~cm}$ & $1.1 \mathrm{~cm}$ \\
\hline 5 & security & bad & good \\
\hline 6 & efficiency & 1 times & 2.3 times \\
\hline
\end{tabular}

Table 1

\subsection{Conclusion}

The new method (using well camera) need not to do sketch and record outside, it needs only to take picture in the well. so compare to traditional method, it save lot of time. For the safety of staff, the new method can avoid toxic gas damage, On the other hand, reducing working time in complex traffic environment is a way to reduce safety accidents. In the aspect of data management, the new method can save the images and data in two ways to improve retrieval more convenient, rather than the traditional method only save the data. From the aspect of efficiency, the new method is 2.3 times of the traditional method. In terms of measurement accuracy, the new method is consistent with the traditional method.

\section{REFERENCES}

LIN Z J.UAV for Mapping:Low Altitude Photogrammetry Survey. Proceedings of International Society of Photogrammetry and Remote Sensing . 2008.

Feng W H.The Specific Character of Limit Errors in Close Range Photogrammetry. Geo Spatial Information Science Quarterly. 2001.

Tianen Chen, Ryosuke Shibasaki, and Zongjian Lin,A Rigorous Laboratory Calibration Method for Interior Orientation of an Airborne Linear Push-Broom Camera Photogrammetric Engineering \& Remote Sensing . April 2007. 